\title{
A community integrated respiratory team can improve patient care, quality of life and reduce hospital stays
}

\author{
Authors: Michael Apps, Jan Minter, James Whitfield, Sue Field, Ronni Pearce, Mark Haigh, Petra Rosier, Bernadette \\ Hawkes, Loren Ateli, Donna Carter, Sue Webb, Sue Barfield, Paul Bannister, Honorie Olympio-Anang, Carole \\ Goodrich, Jodie Finney and Lelly-Ann Keeling
}

\section{Aims}

To identify the impact of a community integrated respiratory team on early discharge after exacerbation of COPD, need for pulmonary rehabilitation and care provision in the community.

\section{Methods}

A rolling audit of all referrals to the team to identify comorbidity, complexity of disease and need for pulmonary rehabilitation in south-west Essex to support a new integrated service with pulmonary rehabilitation, oxygen services, and in-reach into hospital. Audit of patients reviewed for early discharge on the acute medical unit.

\section{Results}

803 patients were referred to the service from January to July 2015. In addition, from April to July 2015, 66 patients were referred for pulmonary rehabilitation (PR) alone and 166 for oxygen services.

384 (48\%) were referred from hospital, $70 \%$ of inpatients with exacerbations of COPD and 30\% from outpatients. 52\% referrals were from primary care.

$4 \%$ had no comorbidities, $92 \%$ had at least one, average number per patient $2.6,>3$ other significant conditions in $27 \%$. $6.4 \%$ of patients were receiving NIV/CPAP, $14.8 \%$ were on oxygen, $21 \%$ were using nebulised drugs as therapy.

$272(33.8 \%)$ were identified on referral as ideal for pulmonary rehabilitation, and others were identified actively as part of the assessment process, 66 were referred directly for PR as well.

Of 86 patients reviewed in Basildon Hospital acute medical unit (AMU), 14/86 (16.3\%) did not have COPD as their major problem, $52(60.4 \%)$ were too ill for discharge, and 20 were discharged that day (28\% of those with COPD exacerbations).

\section{Conclusions}

In our area of 450,000 people, there are a large number of patients with COPD, admissions to hospital, and a population with a large burden of comorbidity and complexity of disease. We review all who are referred to the team from both primary and secondary care and seek to improve their clinical state, and prevent admission to hospital with exacerbation of their COPD by the use of a local rapid response care team who can assess quickly, visit frequently and provide nebulisers if needed. Our staff attend the local hospital AMU daily Monday to Friday to look for patients for potential early discharge. The hospital uses a care bundle which includes referral to the community respiratory team for all discharged after COPD admission. Prior studies have suggested up to $30 \%$ of patients with COPD exacerbation can be discharged early; we found $28 \%$. Benchmarking studies suggest that few patients with COPD receive pulmonary rehabilitation, including after admission $(10 \%)$.

By identification at referral to the team plus via discharge bundle plus actively identifying candidates for PR at initial assessment, we are seeking to increase uptake of a treatment which improves quality of life and reduces admissions 